\title{
Experimental and Numerical Studies on Tire Tread Block Friction Characteristics Based on a New Test Device
}

\author{
J. Wu, ${ }^{1,2}$ Y. S. Wang, ${ }^{1}$ B. L. Su, ${ }^{1}$ and Q. Liu ${ }^{1}$ \\ ${ }^{1}$ Center for Composite Materials of Harbin Institute of Technology, Harbin 150001, China \\ ${ }^{2}$ Center for Rubber Composite Materials and Structures, Harbin Institute of Technology at Weihai, Weihai 264209, China
}

Correspondence should be addressed to J. Wu; wujian@hitwh.edu.cn

Received 9 May 2013; Revised 17 December 2013; Accepted 19 December 2013; Published 29 January 2014

Academic Editor: Jiangbo Sha

Copyright (c) $2014 \mathrm{~J}$. Wu et al. This is an open access article distributed under the Creative Commons Attribution License, which permits unrestricted use, distribution, and reproduction in any medium, provided the original work is properly cited.

A new device was developed for tire tread block slip friction tests. Then the friction characteristics were investigated under different loads and contact roads. Based on this, a friction model for contact between tire tread block and different road surfaces was developed. A finite element slip friction model of rubber block was developed for studying the tread contact stress, stiffness under different pattern slope angles, and ditch radius. Results indicate that friction coefficient between tread and ice road increases when the temperature decreases; different tread patterns have a certain influence on the friction coefficient; its average difference was less than $10 \%$. Different roads impact the coefficient of friction more significantly; the greater the pattern slope, the greater the radial stiffness.

\section{Introduction}

Rubber friction is a topic of huge practical importance, for example, for tires, rubber seals, wiper blades, conveyor belts, and syringes [1-7]. In the tire application, tread friction is a very important criterion for tire design, which is composed of many grooves and blocks in complex pattern for the sake of major tire running performances such as traction, braking, riding comfort, and the hydroplaning [1]. Tread rubber friction differs in many ways from the frictional properties of most other solids due to the very low elastic modulus and the high internal friction. The friction force between rubber and road surface has two contributions commonly described as the adhesion and hysteretic components, respectively. The hysteretic component results from the internal friction of the rubber. The adhesion component is important only for clean and relative smooth surfaces [8]. Persson $[2,9,10]$ studied both the adhesion and hysteretic components of rubber friction. Sliding friction for rubber on surfaces with different types of surface roughness was investigated. Rubber friction on rough and smooth surfaces was studied by Pinnington [11]. Here, a hysteresis sliding model was presented in which the friction force was determined by the slope of a peak at the contact line and the contact length at each slip speed.
Heinrich and Klüppel [4] studied the role of rubber friction in tire traction with special emphasis on the load and velocity dependence of the friction coefficient.

The use of numerical analysis techniques has become a quite convenient and powerful tool in mechanical engineering for tire design and development, such as the Finite Element Method (FEM). The most crucial aspect of a tire simulation is the realistic description of the processes in the contact interface between the tire's tread and the road surface. Hofstetter et al. [12] developed a simulation model for sliding tread blocks under consideration of thermal effects and abrasion by means of the FEM in a thermomechanically coupled manner. Good agreement of the computed abrasion patterns with abrasion marks observed at the tread of real tires further underlines the suitability of the model predictions. Modeling strategies and algorithms have been presented by Goda [13] for the numerical prediction of hysteretic friction of rubber components subjected to sliding friction.

In the present paper, we focus on the role of rubber friction in tire tread traction with special emphasis on the loads, road surfaces, and tread patterns dependence of the friction coefficient. In the first part, we developed a new device for tread block friction tests and analyzed the influence of loads, road types, and tread patterns on the tread block 


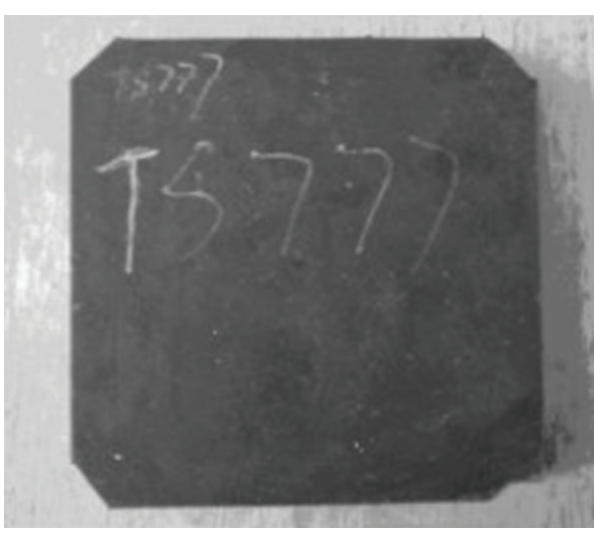

(a) No pattern

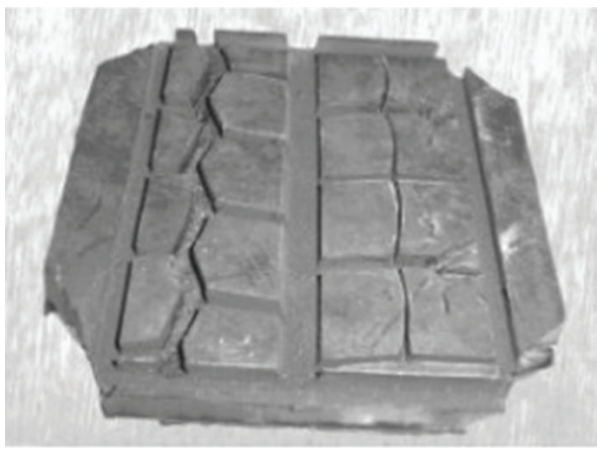

(c) RSD2-A pattern

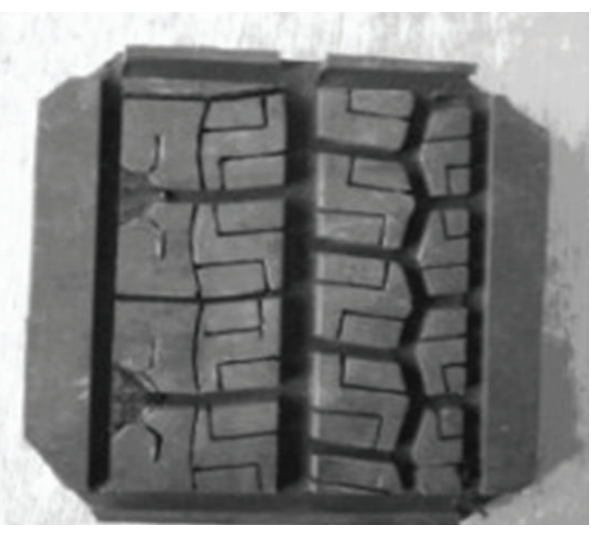

(b) RSD2 pattern

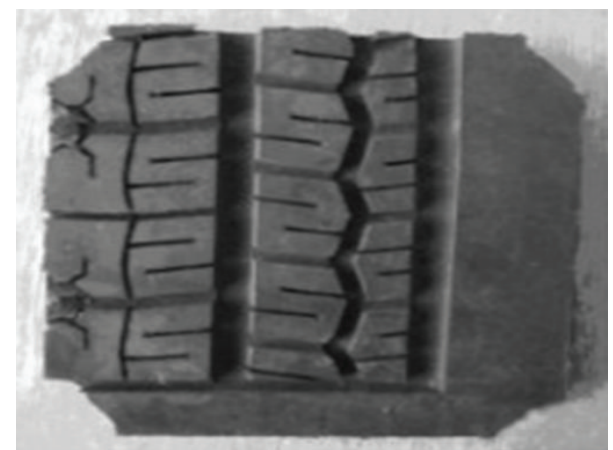

(d) RSD2-B pattern

FIgURE 1: Rubber samples.

rubber friction coefficient. In the second part, we developed a friction model for estimating the load dependence of the friction coefficient without considering the speed. In the last part of the paper, a finite element slip friction model for tread block of a single tire pattern intercept was developed for studying the tread contact stress, stiffness under different pattern slope, and ditch radius.

\section{Friction Characteristics of Tread Block}

Prediction of wear mechanisms of tires requires detailed knowledge about the contact mechanics of tire treads [4]. These studies can be done by extensively testing tires under different conditions. Therefore, Coulomb's friction law is still often used in finite element simulations $[14,15]$. It is clear that rubber friction depends on various parameters such as contact pressure, sliding velocity, temperature, and surface roughness. So Coulomb's law is not sufficient to model rubber friction [16]. To overcome this limitation, a tread friction test device is developed to study the friction characteristics.

2.1. Tread Rubber and Road Samples. The tread rubber samples are provided by Double Coin holdings Ltd, which including styrene butadiene rubber (100 phr), $\mathrm{ZnO}(3 \mathrm{phr})$, stearic acid (2 phr), sulphur (1.5 phr), N-Cyclohexyl-2-benzothiazole sulfonamide (1.5 phr), and carbon blacks ( $50 \mathrm{phr})$. Figure 1 shows the four tread types of rubbers $0.1 \times 0.1 \times 0.01 \mathrm{~m}$
TABLE 1: The properties of asphalt road samples.

\begin{tabular}{lccc}
\hline Road type & $\begin{array}{c}\text { Best asphalt } \\
\text { consumption (\%) }\end{array}$ & Void ratio (\%) & $\begin{array}{c}\text { Max-grain size } \\
(\mathrm{mm})\end{array}$ \\
\hline AC 13 & 4.2 & 4.0 & 13.2 \\
AC 16 & 4.3 & 4.3 & 16 \\
SMA 13 & 5.7 & 3.5 & 13.2 \\
SMA 16 & 5.8 & 3.7 & 16 \\
OGFC 13 & 5.4 & 20 & 13.2 \\
OGFC 16 & 5.5 & 22 & 16 \\
\hline
\end{tabular}

used in tests, which are the smooth pattern, RSD2 pattern, RSD2-A pattern, and RSD2-B pattern. Eight road types $0.3 \times$ $0.3 \times 0.05 \mathrm{~m}$ are used in tests (seen in Figure 2), which are the cement concrete pavement (smooth cement and coarse cement), dense-graded asphalt mixtures (AC13 asphalt, AC16 asphalt), stone matrix asphalt (SMA13 asphalt and SMA16 asphalt), and open-graded friction courses (OGFC13 asphalt and OGFC16 asphalt). The properties of asphalt road samples are shown in Table 1 . Besides, the ice road is made in a square wooden box (seen in Figure 3 ) under the temperature $-20^{\circ} \mathrm{C}$. The rubber blocks are glued to a steel holder in friction tests. The roads are firstly put into the square wooden box (seen in Figure 3 ) and then water is added on the roads for wet friction test. 
TABLE 2: Average friction coefficients.

\begin{tabular}{|c|c|c|c|c|c|}
\hline \multirow{2}{*}{ Road type } & \multirow{2}{*}{ Tread type } & \multicolumn{4}{|c|}{ Average friction coefficient } \\
\hline & & Dry & Std dev & Wet & Std dev \\
\hline Coarse cement & No pattern & 1.19 & 0.0152 & 1.02 & 0.0162 \\
\hline Coarse cement & RSD2 pattern & 1.18 & 0.0148 & 1.01 & 0.0153 \\
\hline Coarse cement & RSD2-A pattern & 1.17 & 0.0156 & & \\
\hline Coarse cement & RSD2-B pattern & 1.31 & 0.0162 & & \\
\hline Smooth cement & No pattern & 0.65 & 0.0135 & & \\
\hline Smooth cement & RSD2 pattern & 0.79 & 0.0147 & & \\
\hline AC13 asphalt & No pattern & 1.31 & 0.0173 & 1.11 & 0.0161 \\
\hline AC13 asphalt & RSD2 pattern & 1.45 & 0.018 & 1.25 & 0.0163 \\
\hline SMA16 asphalt & No pattern & 1.41 & 0.0167 & 1.27 & 0.0154 \\
\hline SMA16 asphalt & RSD2 pattern & 1.45 & 0.0192 & 1.26 & 0.0173 \\
\hline OGFC13 asphalt & No pattern & 1.22 & 0.0172 & 1.08 & 0.0165 \\
\hline OGFC13 asphalt & RSD2 pattern & 1.36 & 0.0189 & 1.150 & 0.0158 \\
\hline OGFC16 asphalt & No pattern & 1.06 & 0.0182 & & \\
\hline OGFC16 asphalt & RSD2 pattern & 1.17 & 0.0173 & & \\
\hline
\end{tabular}

TABLE 3: Average friction coefficients between ice and tread.

\begin{tabular}{lccccccc}
\hline \multirow{2}{*}{ Road type } & \multirow{2}{*}{ Tread type } & $-2^{\circ} \mathrm{C}$ & Std Dev & $-10^{\circ} \mathrm{C}$ & Std dev & $-15^{\circ} \mathrm{C}$ & Std dev \\
\hline Ice & No pattern & 0.19 & 0.0124 & 0.23 & 0.0127 & 0.39 \\
Ice & RSD2 pattern & 0.21 & 0.0131 & 0.27 & 0.0134 & 0.41 \\
Ice & RSD2-A pattern & 0.17 & 0.0125 & 0.25 & 0.0137 & 0.0132 \\
Ice & RSD2-B pattern & 0.18 & 0.0132 & 0.28 & 0.0128 & 0.37 \\
\hline
\end{tabular}

TABLE 4: Input parameters for tread block and load.

\begin{tabular}{lcccc}
\hline $\begin{array}{l}\text { Sliding velocity } \\
v(\mathrm{~m} / \mathrm{s})\end{array}$ & $\begin{array}{l}\text { Load } F \\
(\mathrm{~N})\end{array}$ & $\begin{array}{l}\text { Ditch radius } \\
r_{d}(\mathrm{~mm})\end{array}$ & \multicolumn{2}{c}{ Slope angles } \\
& 1000 & 1.5 & 6 & 8 \\
0.4 & 4000 & 3 & 12 & 14 \\
& 7000 & 4.5 & 16 & 18 \\
\hline
\end{tabular}

2.2. Tread Friction Device. Figure 4 shows the self-made tread slipping friction test device, which including metal frame, sideways, mass block, tread rubber holder, road fixture, and force sensor. Firstly, the road is clamped on the slider, which is fastened by bolts (seen in Figure 4(b)). Secondly, the tread rubber sample is fixed under the rubber holder and put on the road. Thirdly, the rubber holder is blocked by a steel lever, so the relative sliding movement can be achieved between the rubber sample and the road. Finally, the different mass blocks are added to the rubber holder for friction tests; the friction force is recorded by force sensor when the hand wheel is turned.

2.3. Testing Preparation and Procedure. A series of experiments have been made to investigate the key parameters of friction: rubber tread pattern type, temperature, road type, and loads. There are three loads, $10 \mathrm{~N}, 30 \mathrm{~N}$, and $60 \mathrm{~N}$, in each test. When the rubber and road samples are prepared, the hand wheel is turned at constant velocity and the friction forces are recorded and repeated 10 times. Based on the test results, the friction model can be developed.

2.4. Results and Discussion. Table 2 shows the average friction coefficient in tests at room temperature. One of each road type is used for wet friction test. It can be seen that different patterns have a certain influence on the friction coefficient; its average difference is less than $10 \%$. Different roads impact the coefficient of friction more significantly; the friction coefficient of the ice surface is minimum, followed by the cement road; SMA16 asphalt road is the largest, which is related to its structure; and the friction coefficient reduces when it is tested on the wet road.

Persson [17] developed a theory of rubber friction when a rubber block is slid over a hard rough surface, with roughness on many different length scales $\lambda$. Figure 5 shows the elastic contact between a flat rubber surface and a hard solid substrate. In Figure 5, $\zeta$ is the scaling factor, $\lambda_{0}$ is the upper cut-off length, $h_{0}$ is the amplitude, and $R$ is the radius [17]. Results indicated that the friction coefficient decreased when the length scales $\lambda$ increased. Seen in Table 1 , the void ratio of AC, SMA type roads is smaller than that of OGFC, so the friction coefficient of AC13 asphalt/RSD2 pattern and SMA16 asphalt/RSD2 pattern is the highest due to the smaller $\lambda$ and the larger deformation of pattern. 


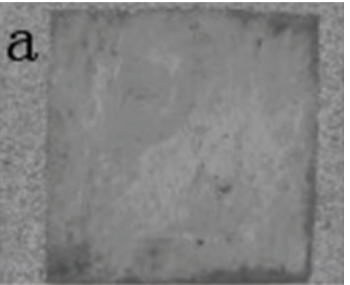

(a) Smooth cement

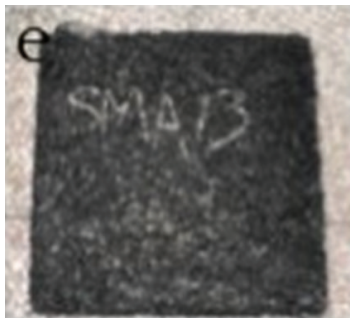

(e) SMA13 asphalt

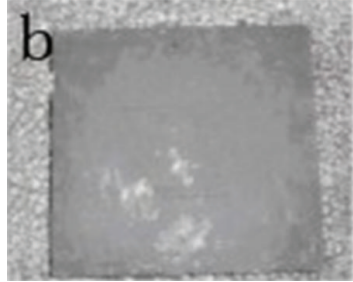

(b) Coarse cement

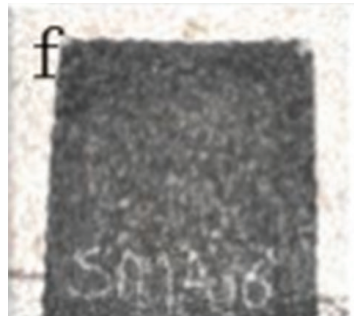

(f) SMA16 asphalt

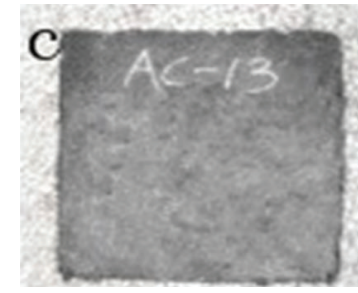

(c) AC13 asphalt

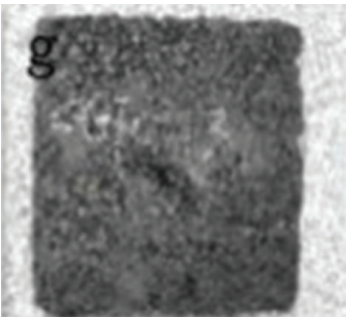

(g) OGFC13 asphalt

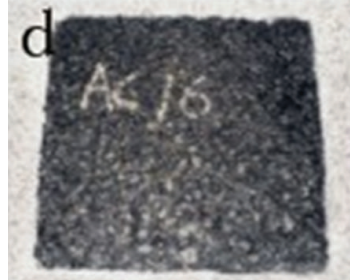

(d) AC16 asphalt

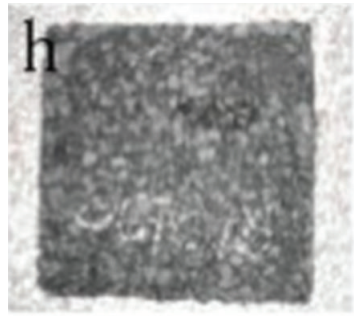

(h) OGFC16 asphalt

Figure 2: Road samples.

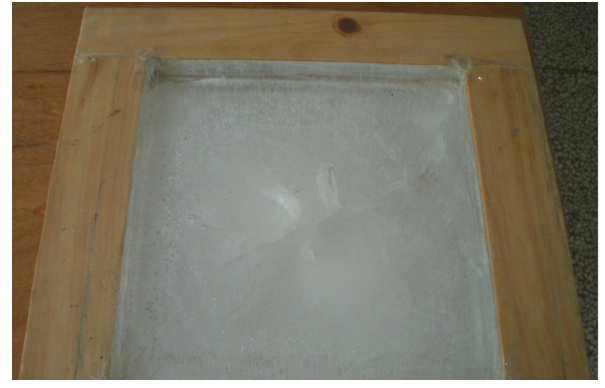

Figure 3: Ice road samples.

Table 3 shows the average friction coefficient between ice road and tread under different temperatures.

Results indicate that the friction coefficient between tread and ice road increases when the temperature decreases due to the increased melt-water lubrication at the ice-rubber interface, similar results have also been given by Skouvaklis et al. [18].

Figures 6 and 7 show the friction forces under different loads between the road and rubber tread.

It can been seen that the friction force increases when the load increases; the friction force of RSD2 pattern is larger than that of no pattern due to the larger deformation in rubber; under the same conditions of load and thread block, the friction force of $\mathrm{ACl} 3$ is larger than that of $\mathrm{AC16}$; however, the friction force of SMA13 is smaller than that of SMA16. It may be the reasons of different road types. Many related studies on the contact between road and rubber have been carried out by Persson $[2,3,6,9,10,17]$. More detailed studies should be carried out in our next work.

2.5. Friction Model. Generally, friction of rubber tread is dependent on both normal pressure and slip velocity. A friction

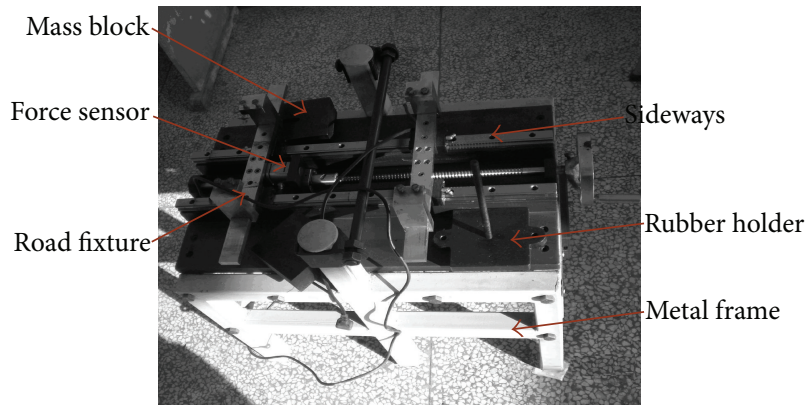

(a) Test device

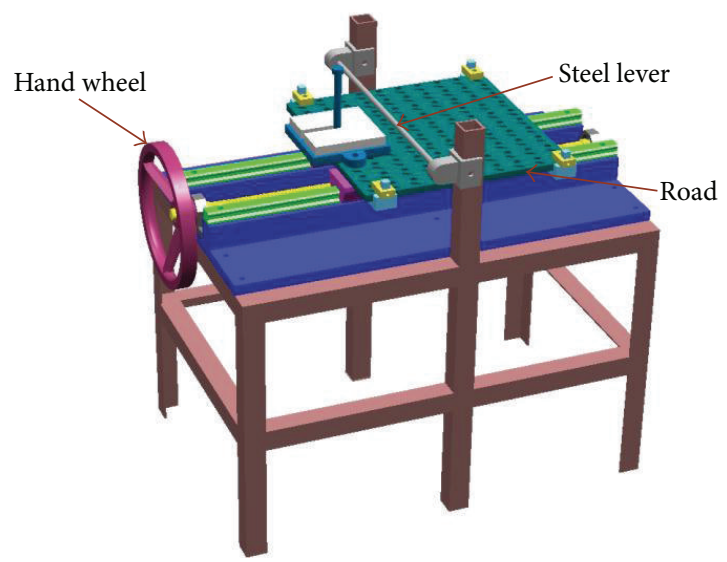

(b) $3 \mathrm{D}$ model

Figure 4: Sliding friction test device.

model is developed in an effort to produce more realistic results based on the Savkoor's friction law [19], which considered the road influence. This friction model is applied in the sliding simulation using the user subroutine VFRIC. 


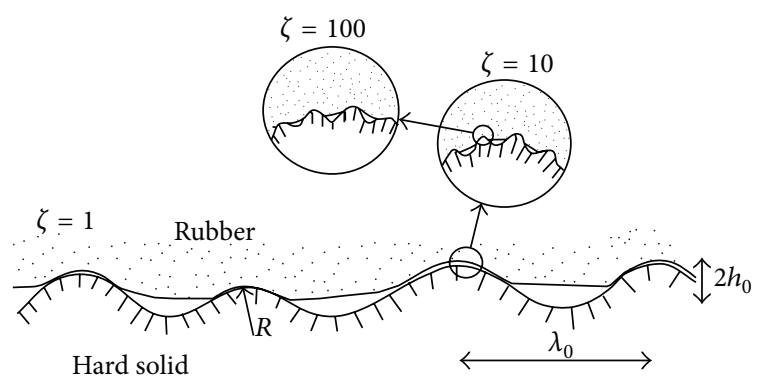

Figure 5: Elastic contact between a flat rubber surface and a hard solid substrate [17].

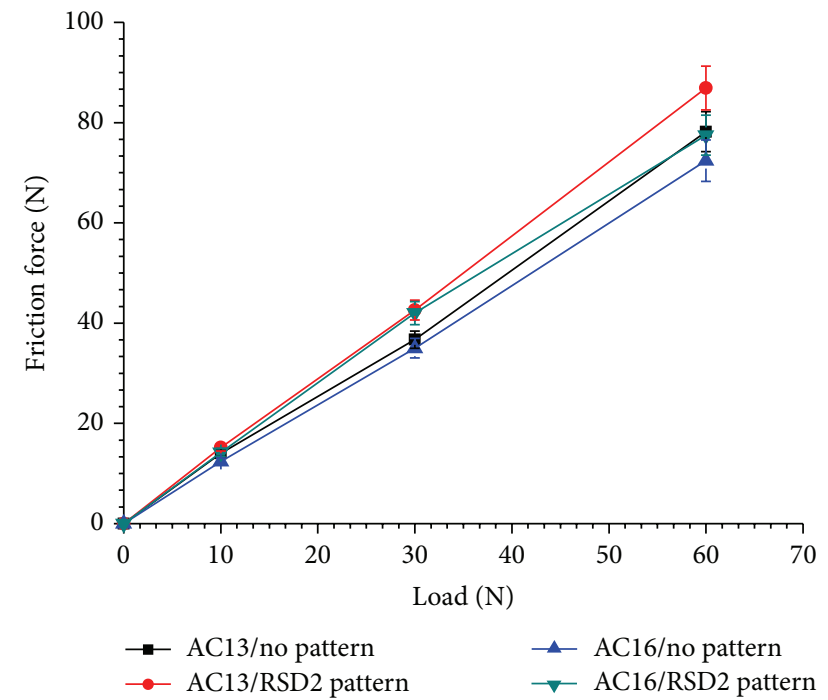

FIGURE 6: Friction forces versus load with AC type roads.

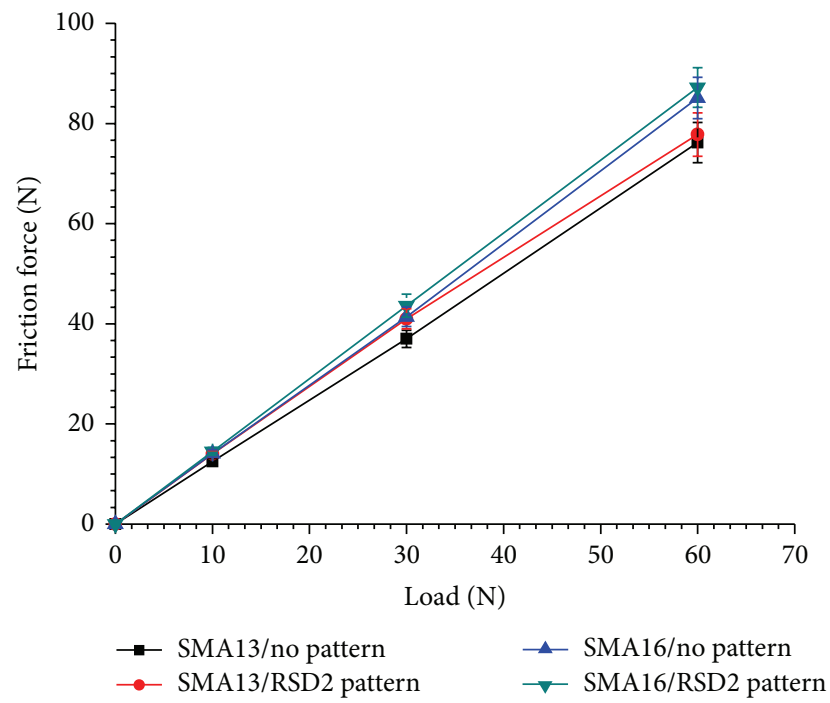

FIgURE 7: Friction forces versus load with SMA type roads.

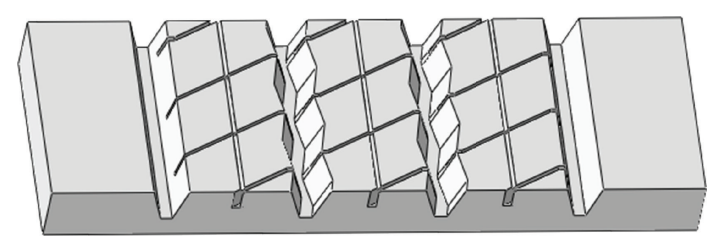

(a) $3 \mathrm{D}$ view

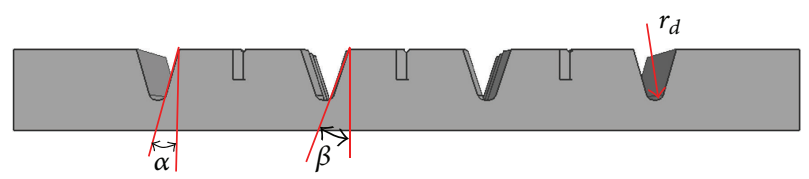

(b) Front view

FIgURE 8: 3D model of tread block specimen.

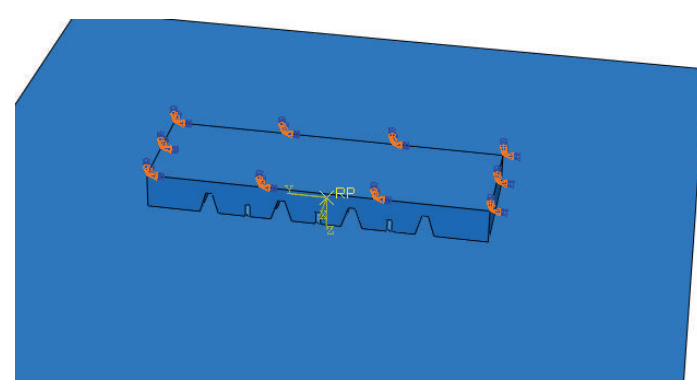

FIGURE 9: Boundaries in the simulation model.

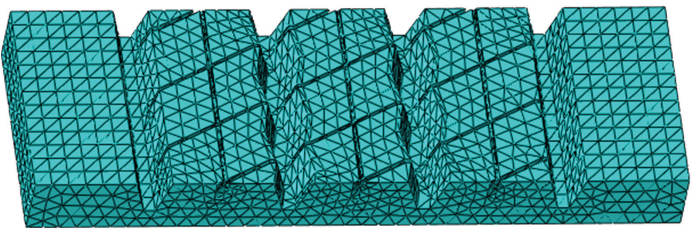

Figure 10: Meshing of the tread block.

The friction model is expanded based on the Savkoor's friction model [19], which is given by

$$
\begin{aligned}
\mu_{d_{i j}}= & K_{r}\left(\frac{p_{i j}}{p_{0}}\right)^{-k} \\
& \times\left[\mu_{0}+\left(\mu_{m}-\mu_{0}\right) \exp \left\{-h^{2} \log ^{2}\left(\frac{\left|v_{i j}\right|}{v_{m}}\right)\right\}\right],
\end{aligned}
$$

where $K_{r}$ is the road structure parameter, which is the friction coefficient ratio to the test roads, $p_{i j}$ is the normal pressure, $p_{0}$ is the reference normal pressure, $k$ is the pressure exponential factor, $\mu_{0}$ is the starting static friction coefficient, $\mu_{m}$ is the maximum value of friction coefficient neglecting normal contact pressure, $v_{i j}$ is the sliding speed, $v_{m}$ is the scalar sliding speed at maximum friction coefficient, and $h$ is the speed parameter. 


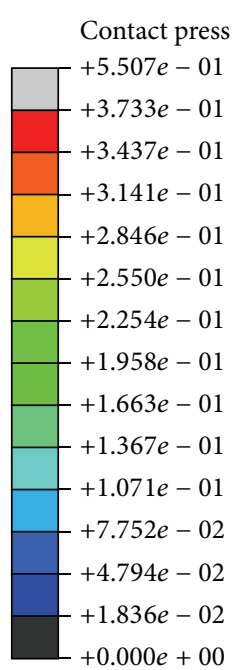

(a) $r_{d}=1.5 \mathrm{~mm}$

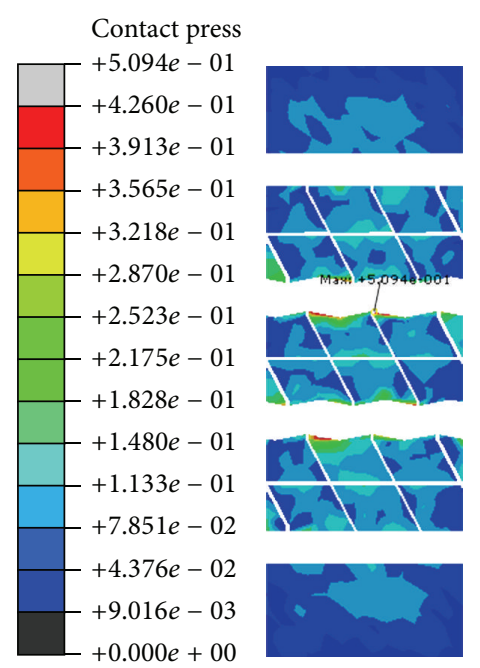

(b) $r_{d}=3 \mathrm{~mm}$

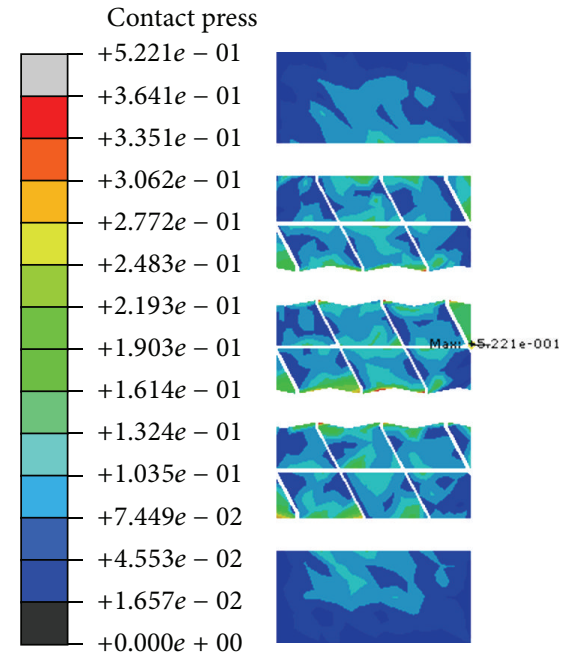

(c) $r_{d}=4.5 \mathrm{~mm}$

FIGURE 11: Contact press of the tread block under different ditch radius.

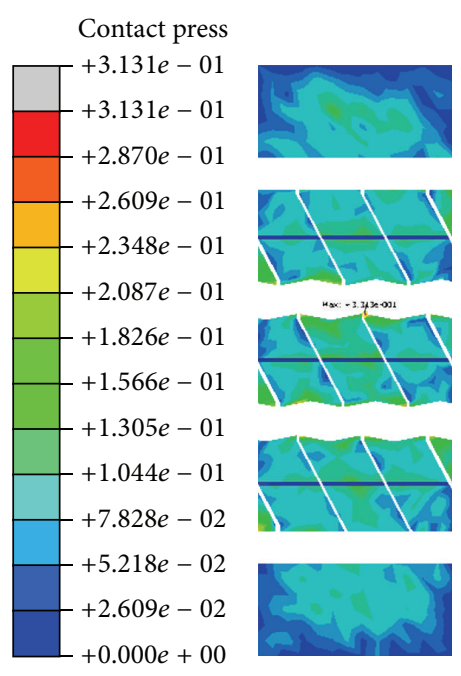

(a) $\alpha=6^{\circ}, \beta=8^{\circ}$
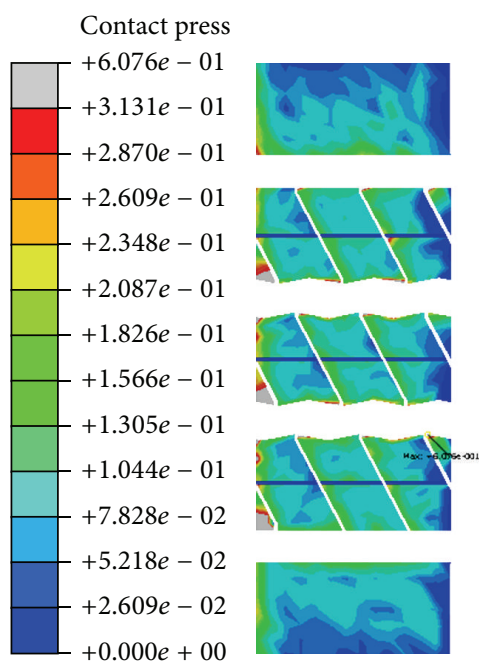

(b) $\alpha=12^{\circ}, \beta=14^{\circ}$

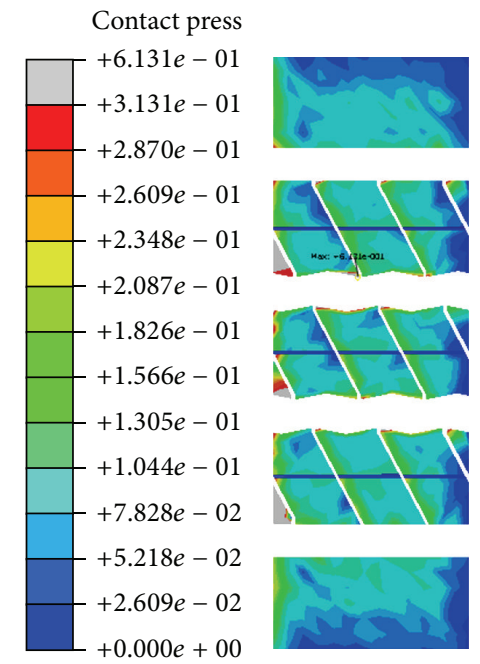

(c) $\alpha=16^{\circ}, \beta=18^{\circ}$

FIGURE 12: Contact press of the tread block under different slope angles.

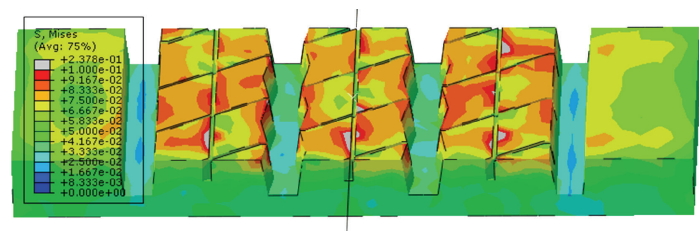

(a) First step

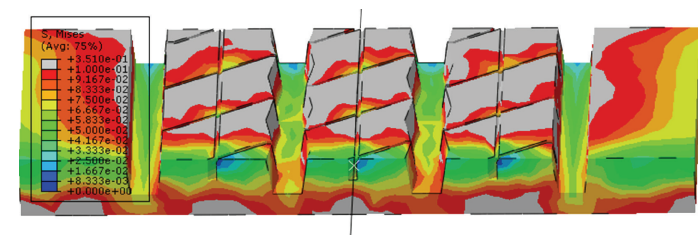

(b) Second step

FIGURE 13: Distribution of von mises stress for tread block under the conditions: $\alpha=6^{\circ}$ and $\beta=8^{\circ}$.

\section{Finite Element Model}

3.1. General Remarks. The numerical simulations of tread block sliding process are carried out by means of the commercial finite element code ABAQUS. Implicit code is chosen in the context of contact problems.
The hyperelastic material behaviour of rubber is characterized by means of Moonley-Rivlin material model; the strain energy density function is defined by

$$
U=C_{10}\left(I_{1}-3\right)+C_{01}\left(I_{2}-3\right)+\left(\frac{1}{D_{1}}\right)\left(J_{\mathrm{el}}-1\right)^{2},
$$




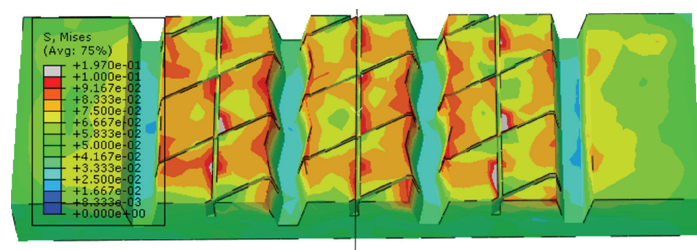

(a) First step

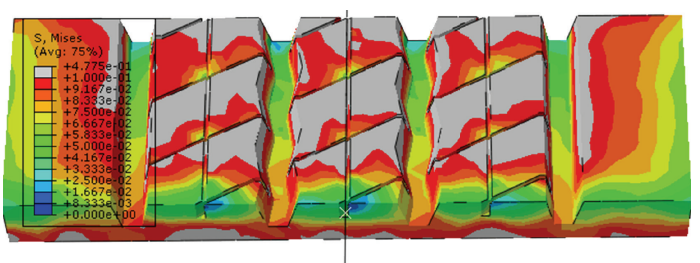

(b) Second step

FIGURE 14: Distribution of von mises stress for tread block under the conditions: $\alpha=12^{\circ}$ and $\beta=14^{\circ}$.

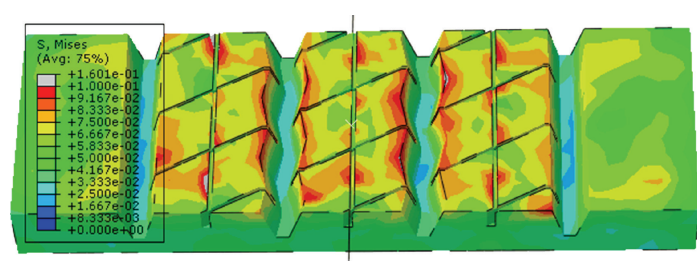

(a) First step

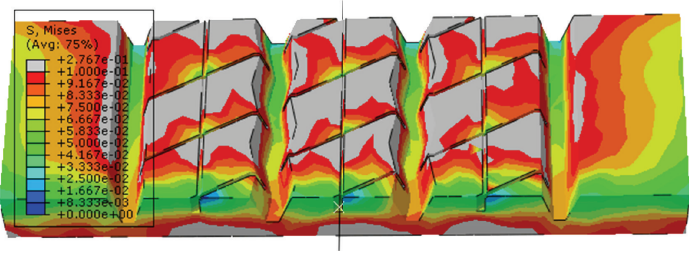

(b) Second step

FIGURE 15: Distribution of von mises stress for tread block under the conditions: $\alpha=16^{\circ}$ and $\beta=18^{\circ}$.

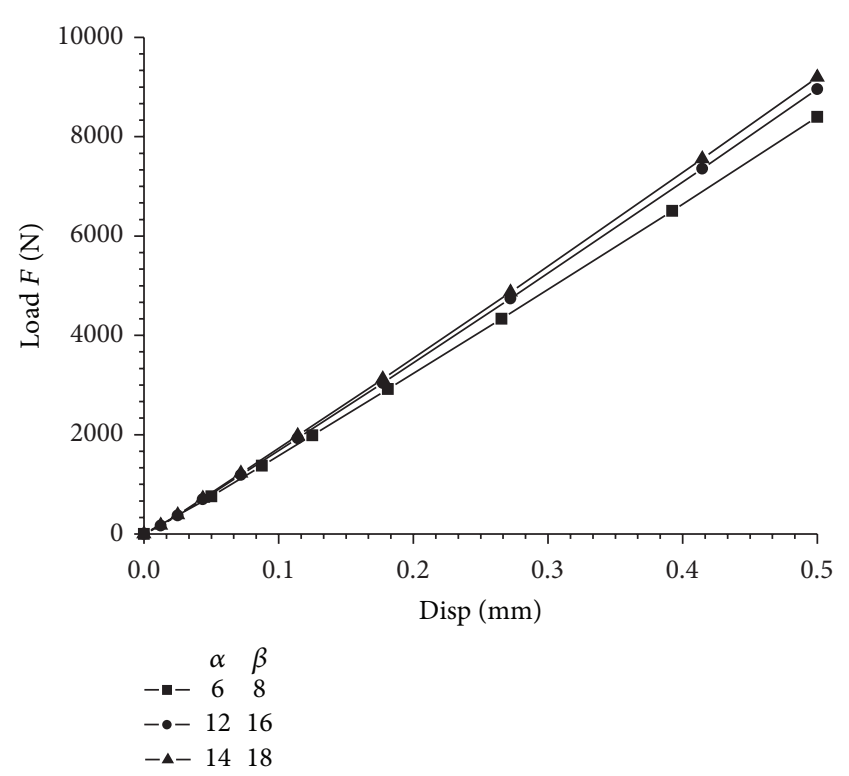

Figure 16: Stiffness curve in $\mathrm{Z}$ direction under different pattern slope angles.

where $U$ is the strain energy density, $C_{10}$ and $C_{01}$ are the rubber material constants determined from experiment, $I_{1}$ and $I_{2}$ are the first and second deviatoric strain invariants, $D_{1}$ is a sort of penalty parameter controlling the rubber incompressibility, and $J_{\mathrm{el}}$ is the elastic volume ratio [20].

The road which constitutes the friction surface is modeled as flat and rigid in the finite element simulations. The tread block with the simplest shape, which constitutes the elementary unit of tire tread pattern intercept. Tread block specimens with three different pattern slope angles $\alpha$ and $\beta$ and ditch radius $r_{d}$ (See in Figure 8 ) are used in simulation, respectively.

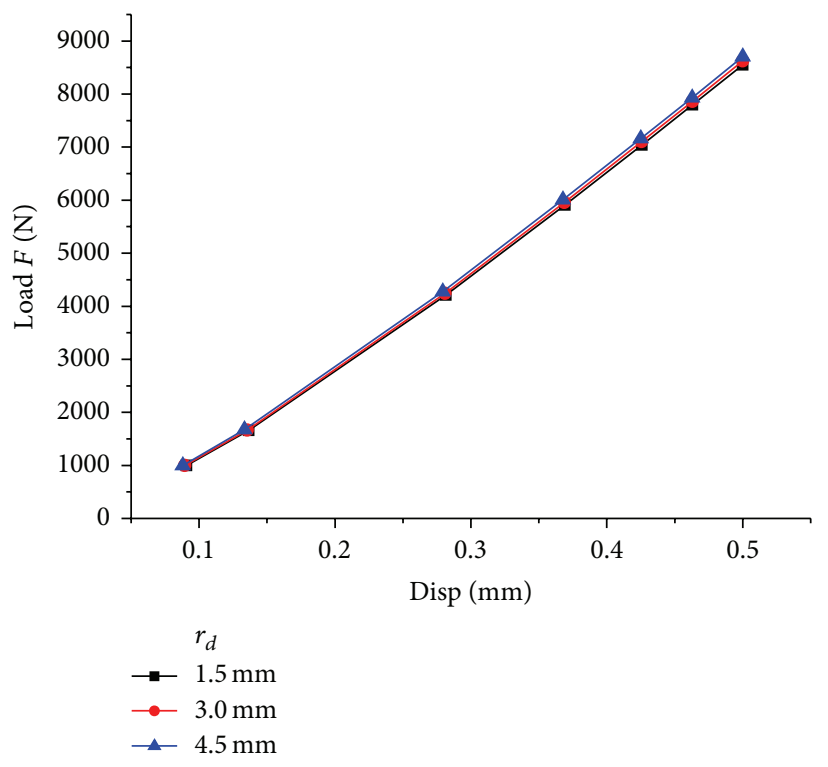

FIGURE 17: Stiffness curve in $\mathrm{Z}$ direction under different ditch radius.

3.2. Boundary and Meshing. The finite element simulation is performed in two steps as illustrated in Figure 9. In the first step, the top surface of the rubber block is fixed in all directions; the reference node RP of the road is fixed in the X and $Y$ directions and is applied as a uniformly load $F$ in the reverse $\mathrm{Z}$ direction. Under maintenance of this load, the block is moved in $\mathrm{X}$ direction at constant sliding velocity $v$ in the second step. Figure 10 shows the meshing of the tread block with the slope angles of $\alpha=6^{\circ}$ and $\beta=8^{\circ}$ and ditch radius of $r_{d}=0 \mathrm{~mm}$. Typical values of the required input parameters for tread block and load are included in Table 4 . 
3.3. Results and Discussion. Figure 11 shows the contact press of the tread block in the first step of simulation under the conditions of $\alpha=6^{\circ}, \beta=8^{\circ}$, and $F=1000 \mathrm{~N}$. Results indicate that the maximum contact press decreases firstly and then increases with the increasement of the ditch radius $r_{d}$. However, there is no significant effect on the overall.

The influence of the tread block geometry on the deformation and the mechanical behaviour is investigated by finite element method. Figure 12 shows the contact press of the tread block in the first step of simulation under the conditions of $r_{d}=1.5 \mathrm{~mm}$ and $F=1000 \mathrm{~N}$.

It can be seen that the maximum contact press increases with the increasement of the slope angles.

Figures 13, 14, and 15 show the von mises stress distribution of the tread block under the load of $1000 \mathrm{~N}$ and three different pattern slope angles, respectively.

It can be seen that the von mises stress on the top surface of the tread block in the second step of the simulation process is larger than that in the first step. Because the tread block is sliding on the road with $v=0.4 \mathrm{~m} / \mathrm{s}$ in the second step, the deformation increases due to the rubber friction force. Furthermore, the von mises stress decreases when the slope angle increases. The reason may be that the larger slope angle improves the normal stiffness ( $\mathrm{Z}$ direction) of the tread block, which can be seen in Figure 16. However, the effect of ditch radius on the normal stiffness of the tread block is not obvious (see in Figure 17).

Figure 18 shows the curves of the friction force to the sliding distance under different loads $F$. Results indicate that stiffness in $\mathrm{X}$ direction slightly increases with the increasing of the load. It can also be seen that the calculated friction coefficient is not changed much under different loads.

\section{Conclusions}

Numerical simulations have become an important tool in the design and development of tire. This paper shows the capabilities of numerical methods within the framework of tread block friction characteristics and mechanics. It concentrates on the sliding motion of rubber tread blocks on different road surfaces. Furthermore, a new sliding friction test device is developed for studying the tread block friction characteristics. According to experimental results and the analyses above, we have the following points.

(1) Different patterns have a certain influence on the friction coefficient; its average difference was less than $10 \%$. Different roads impact the coefficient of friction more significantly due to the different length scales.

(2) The friction coefficient reduces when it tests on the wet road; the friction coefficient between tread and ice road increases when the temperature decreases.

(3) The maximum contact press decreases firstly and then increases with the increasement of the ditch radius; the von mises stress of the tread block increases obviously when it is sliding and decreases when the slope angle increases.

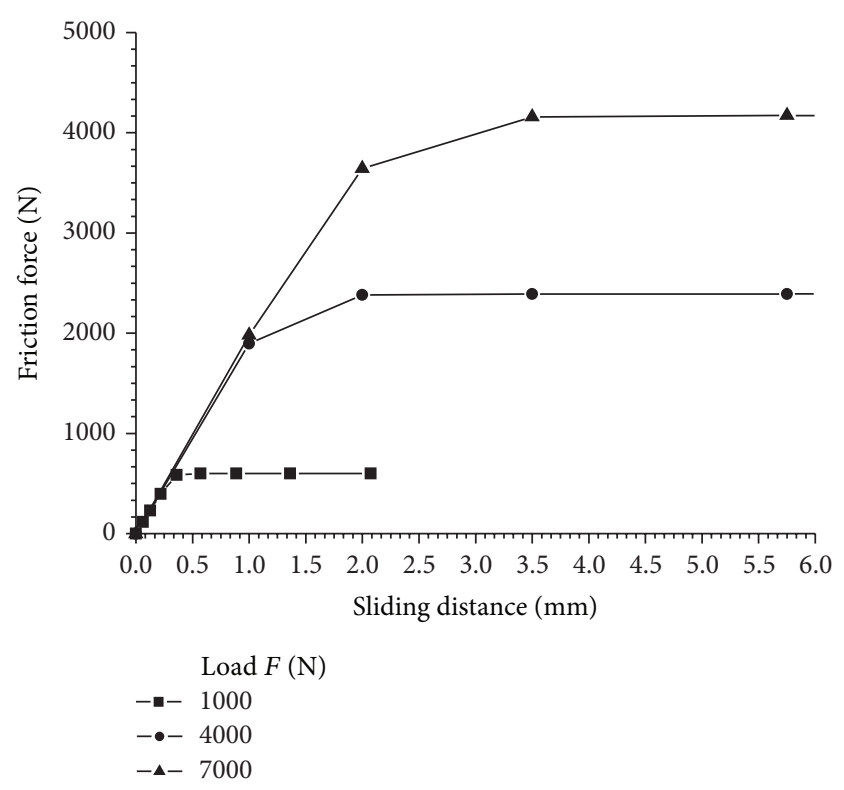

FIGURE 18: Friction force curves in X direction under different loads.

(4) The normal stiffness of the tread block increases when the slope angle increases; however, the effect of ditch radius on that is not obvious.

(5) Numerical simulations enable the investigation of a wide range of input parameters very easily and quickly, in these respects, are complementary to tests. It makes the numerical simulations a powerful tool in tire design and development.

\section{Conflict of Interests}

The authors declare that there is no conflict of interests regarding the publication of this paper.

\section{Acknowledgments}

This work is funded by the Natural Science Foundation of China 11142011, Joint construction project of HIT-Weihai 2013DXGJ02, and Double Coin holdings Ltd.

\section{References}

[1] S. K. Clark, Mechanics of Pneumatic Tire, Government Printing Office, Washington, DC, USA, 1982.

[2] B. N. J. Persson, Sliding Friction: Physical Principles and Applications, Springer, Heidelberg, Germany, 2nd edition, 2000.

[3] B. N. J. Persson, "Rubber friction: role of the flash temperature," Journal of Physics Condensed Matter, vol. 18, no. 32, pp. 77897823, 2006.

[4] G. Heinrich and M. Klüppel, "Rubber friction, tread deformation and tire traction," Wear, vol. 265, no. 7-8, pp. 1052-1060, 2008 . 
[5] A. Le Gal, X. Yang, and M. Klüppel, "Evaluation of sliding friction and contact mechanics of elastomers based on dynamicmechanical analysis," The Journal of Chemical Physics, vol. 123, Article ID 014704, 2005.

[6] B. N. Persson, "Rolling friction for hard cylinder and sphere on viscoelastic solid." The European Physical Journal E, vol. 33, no. 4, pp. 327-333, 2010.

[7] B. Lorenz, B. N. J. Persson, S. Dieluweit, and T. Tada, "Rubber friction: comparison of theory with experiment," The European Physical Journal E, vol. 34, no. 12, article 129, 2011.

[8] D. F. Moore, The Friction and Lubrication of Elastomer, Pergamon, Oxford, UK, 1972.

[9] B. N. J. Persson, "On the theory of rubber friction," Surface Science, vol. 401, no. 3, pp. 445-454, 1998.

[10] B. N. J. Persson and E. Tosatti, "Qualitative theory of rubber friction and wear," The Journal of Chemical Physics, vol. 112, no. 4, pp. 2021-2029, 2000.

[11] R. J. Pinnington, "Rubber friction on rough and smooth surfaces," Wear, vol. 267, no. 9-10, pp. 1653-1664, 2009.

[12] K. Hofstetter, C. Grohs, J. Eberhardsteiner, and H. A. Mang, "Sliding behaviour of simplified tire tread patterns investigated by means of FEM," Computers and Structures, vol. 84, no. 17-18, pp. 1151-1163, 2006.

[13] T. J. Goda, "Numerical prediction of friction, wear, heat generation and lubrication in case of sliding rubber components," in Towards Intelligent Engineering and Information Technology, vol. 243, pp. 519-530, Springer, 2009.

[14] K. Rao, R. Kumar, and P. Bohara, "Transient finite element analysis of tire dynamic behavior," Tire Science and Technology, vol. 31, no. 2, pp. 104-127, 2003.

[15] O. A. Olatunbosun and O. Bolarinwa, "FE simulation of the effect of tire design parameters on lateral forces and moments," Tire Science and Technology, vol. 32, no. 3, pp. 146-163, 2004.

[16] R. van der Steen, I. Lopez, H. Nijmeijer, A. J. C. Schmeitz, and B. de Bruijn, "Experimental and numerical study of friction and braking characteristics of rolling tires," Tire Science and Technology, vol. 39, no. 2, pp. 62-78, 2011.

[17] B. N. J. Persson, "Theory of rubber friction and contact mechanics," The Journal of Chemical Physics, vol. 115, no. 8, pp. 3840-3861, 2001.

[18] G. Skouvaklis, J. R. Blackford, and V. Koutsos, "Friction of rubber on ice: a new machine, influence of rubber properties and sliding parameters," Tribology International, vol. 49, pp. 4452, 2012.

[19] A. R. Savkoor, "On the friction of rubber," Wear, vol. 8, no. 3, pp. 222-237, 1965.

[20] Abaqus Software, Abaqus Theory Manual, Abaqus, Providence, RI, USA, 2005. 

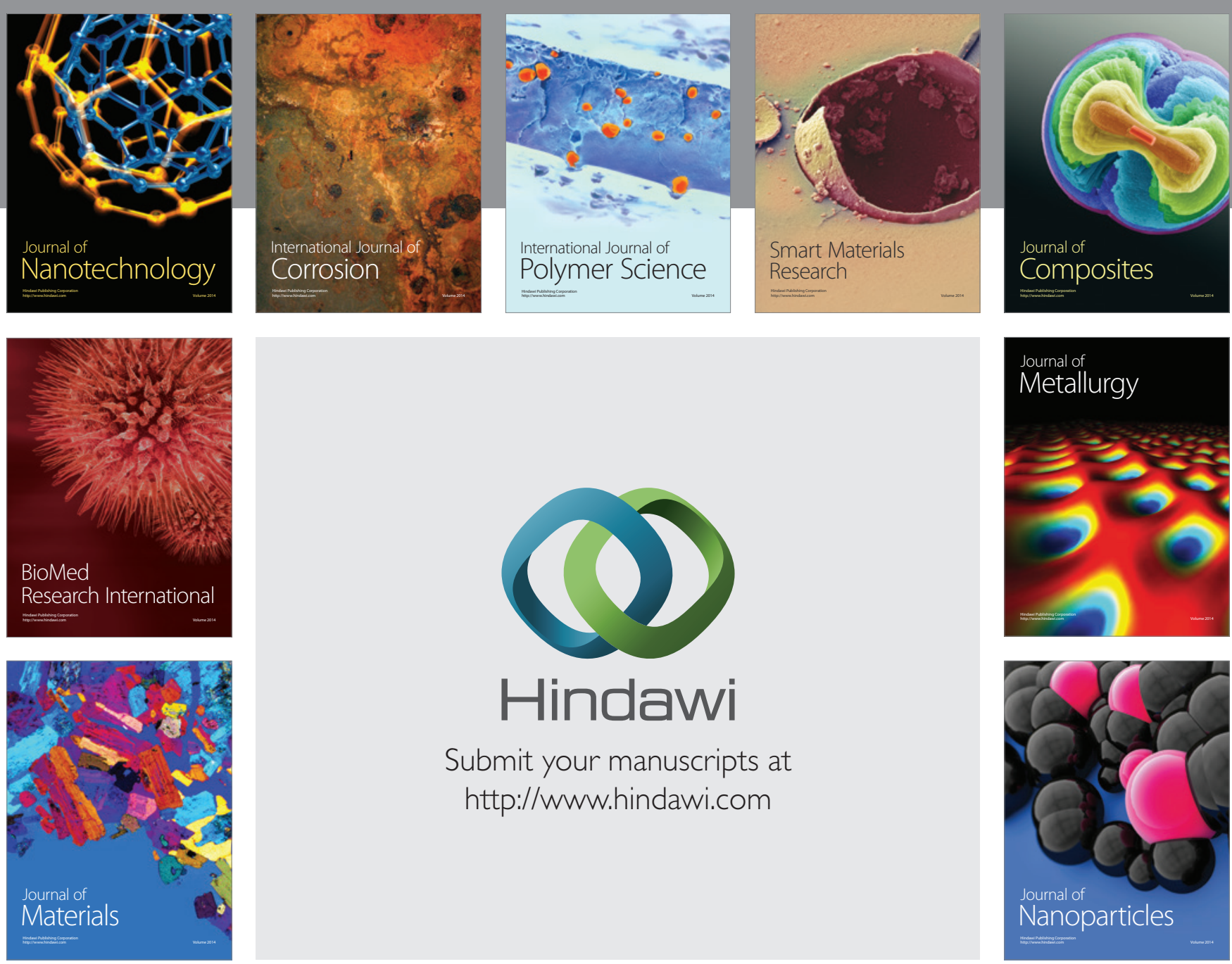

Submit your manuscripts at http://www.hindawi.com
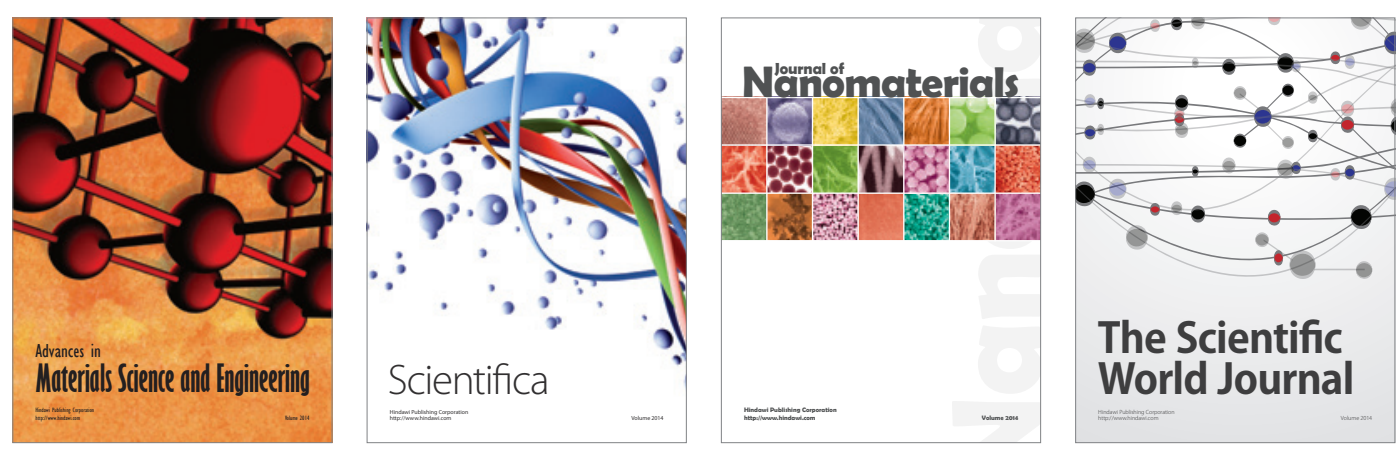

\section{The Scientific World Journal}
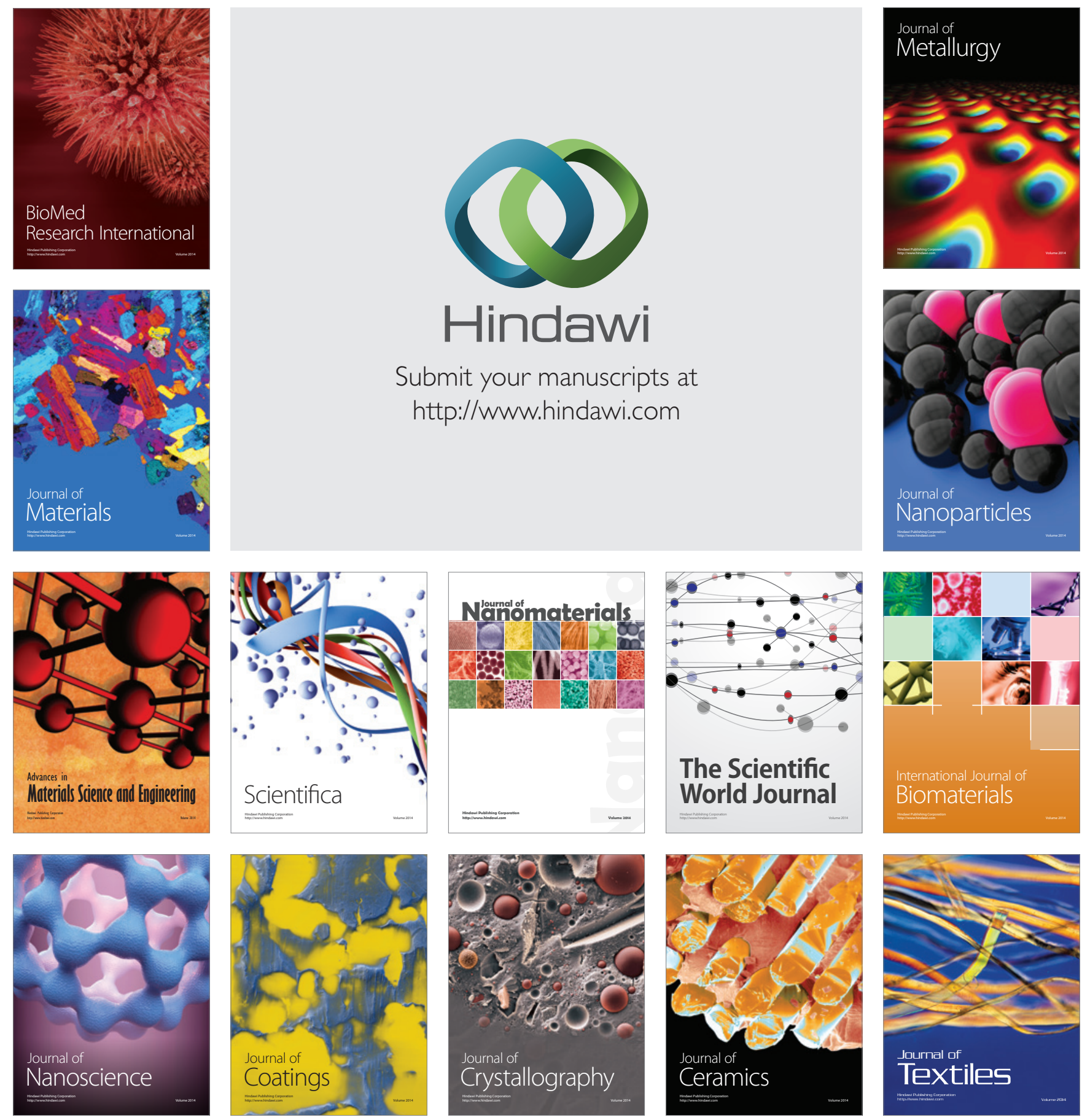